\title{
Investigating the Influence of Video Games on EFL Learners' Motivation in the Saudi Context
}

\begin{abstract}
Nasser M Asiri
Abha Technical College TVTC, Saudi Arabia

Received: November 5, 2019 Accepted: December 7, 2019 Published: December 12, 2019

doi:10.5296/jsel.v8i1.16022ＵRL: https://doi.org/10.5296/jsel.v8i1.16022

Abstract

Since English Language has become the dominate language of science, education, finance and entertainment, most non-English speaking countries have adopted English language curriculums in schools and colleges as a second or a forging language. These curriculums have presented materials in the form of textbooks accompanied by videos and audios to give an enriching learning experience. As recreational video games is an expanding industry with its economic and cultural aspects throughout the world, they are used as a source of learning the English language. This paper aims to investigate the influence of video games on motivating learners to learn the English language. The study has been conducted in a trainees college of Technology in Saudi Arabia. A survey questionnaire was conducted to collected data from the participants. The key findings suggest that learners are keen on using the video games as a means of learning the English language.
\end{abstract}

Keywords: EFL context, Second language learning, Survey questionnaire, Video games 


\section{Introduction}

Since the rise of the United States as a superpower, English has become the global language of science, academia, research, global trade, technology, manufacturing, diplomacy, internet, and entertainment. It has become a part of everyday life due its wide usage across different fields. Recognizing its crucial role in various fields, educational systems across the world have adapted the teaching of English language as a second or a foreign language in order to equip learners with essential communicative competence. In educational institutions, learners are encouraged to acquire the new language for multiple reasons, such as having a better chance in continuing postgraduate studies, finding and securing a job, enhancing one's intellect or simply interacting with growing amount of entertainment presented in the English language.

After the 9/11, English language has taken a special place in the Saudi educational policy. It has been given the status of the most important and mandatory foreign language to be learnt by all students in secondary and tertiary institutions. It was introduced as a foreign language with the aim of developing the communicative competence of the EFL students gradually throughout compulsory education that includes the elementary, intermediate and secondary schooling. The students are exposed to English language classes at an early age of seven in primary schools. On average, the public educational system introduces English language in the fourth grade that continues to the final year of the secondary school with the amount of eight years of exposure to English language in total. At the university level, the learners usually have 18 hours of English language learning per week in the foundation year program. Their performances are assessed through continuous formative and summative assessment in the form of midterm and final examinations.

At the undergraduate stage in technical colleges, the Saudi EFL students are exposed to English language in three or four courses, which are specifically designed to meet the needs of the labor market and equip them with technical English to encounter the potential need of the occupation. These needs are addressed through tailored ESP (English for Specific Purposes) courses, which focus on the EFL learners' communicative skills, particularly vocabulary items that are related to their professional fields. Nevertheless, these ESP courses also aim to develop learners' reading, writing, listening and speaking skill which are being taught through integrated syllabus.

As English language is the most popular means of communication, it has been used in a variety of forms in classroom environment. For example, English language materials are often combined with entertainment tools to make the language learning experience an enjoyable one. These tools include the use of audio and video materials which help break the boredom and passiveness among the language learners. In the field of foreign language learning, the American entertainment industry is the dominate provider of English language entertainment material to other English-speaking countries, through YouTube, Netflix and other social media websites. These examples of video materials can be utilized by teachers in English language teaching situations to deliver ESP lessons in an enjoyable context to motivate learners and facilitate foreign language learners. 


\section{MInstitute ${ }^{\text {Mink }}$}

Influencing the motivation of learners is the main objective of any learning lesson, therefore, teachers try to provide additional material in their teaching strategy beginning with visual aids, such as flash cards, posters, and audios materials. These resources are considered authentic materials as they are based on the native speakers' phrases, conversations, and role plays. Today the websites which provides video content is widely used among English language teachers as these resources have benefits, such as providing learners a better experience of English language environment. YouTube is an example of an updated, free and a rich platform with readily accessible content dedicated to all EFL learners.

As part of the authentic materials, video games are considered a modern and widely used tool of entertainment to the new generation. The chief purpose of recreational video games gradually developed from simple tasks to more complex and interactive ones with amazing graphics and exciting storylines. This development resulted in increasing number of players both for young and adults, as the giant leap in improving games shifted from dedicated player machines in stores to their living rooms. Moreover, these gaming consoles are more advanced to the extent that an intense competition between rival companies resulted in presenting highly creative games with cinematic scenarios that captivate players in an interactive environment. In a highly interactive environment, these players could watch, listen, and respond to commands and follow the storyline in order to complete tasks and overcome stages in the video games.

This expanding mean of entertainment is dominated by the lingua franca of today, which is English language. The materials are presented in the form of video games which are considered cultural icons to gamers worldwide. Since these materials have a cultural significance, the nature of the games motivates players all around the world to try understanding what is being written and narrated in the game. This effort engages youngsters and adults in visual media, such as YouTube or Twitch to watch video games by understanding the storyline and presenting it in English before translating it into their own words.

With the availability of video games through different consoles and to present the adjusted versions of iconic games to be played on smartphones and tablets, gaming is now accessible all the time with the feature of multiple players on gaming platforms where they can communicate to achieve certain tasks. In addition to comprehending written instructions, players need to develop communicative skills to interact with their team members.

The above discussion yields two key questions whether video games have any influence on the learners' motivation to learn the English language. Secondly, can teachers consider video games as a tool of motivating new generation of English language learners?

In order to answer the above questions, this article reviews previous studies on motivation in second language learning, which helps develop the theoretical foundation of the paper. The article will establish the relationship between video games and learning and understand how it may influence the motivation of the learners in other contexts. 


\section{Literature Review}

Literature illustrates a wide range of definitions that show various aspects of motivation for language learning in a target culture. Gardner (1985) defines motivation as the extent ones strive to acquire the language due to the desire to learn along with the satisfaction derived from it. Similarly, Harmer (1991) considers "motivation as an internal drive that pushes someone to do something, this definition shows a psychological aspect within the learner needs to be fulfilled whether its success, better job, or self-improvement" (p. 3). In the same way, Pranson, Hinson and Brown $(2001,28)$ define motivation as "an important component or factor in the learning process, they added that learning and motivation have the same importance in order to achieve something" (p. 28).

Researchers divides motivation into two main categories; intrinsic and extrinsic motivation. Ryan and Deci (2000) identify the difference between intrinsic motivation and extrinsic motivation. Intrinsic motivation refers to interesting factors within the action which leads to inherent motivation, such as playing video games. On the other hand, extrinsic motivation refers to external reasons to perform and complete a certain task or action, such as rewards in completing or penalizing learners for not completing a task.

The above definitions of motivation in general, but to try to relate them to the topic in hand. Doring (2002) stated that learning in a low-affective atmosphere is ideal for children to develop high confident which leads to adopting the language.

In terms of the effects of video games on learners' motivation, Ryan, Rigby, and Przybylski (2006) explain that there is a dearth of empirical research on video games that can trigger language learners' motivation. They also argue that video games are considered intrinsically motivating than the usual consideration of being an extrinsic motivation. This can be interesting to know if the video games have any impact on the Saudi ESP students' language learning motivation.

A number of studies have investigated the influence of video games on the learners' motivation. A study on video game-based learning by Whitton (2010) found that adult learners who were only motivated in game play alone. However, playing video games was less motivating and even de-motivating for the adult learners.

On the other hand, Clark (2000) states that video games along with cartoons attract the attention of language learners. His study indicates that creating a non-threatening atmosphere to present information and maintain potential to encourage communicative skills and thinking process. To highlight its significance, Rudis and Postic (2017) commented on Clark's statement that learning a foreign language while playing video games considered to be effective and highly motivating. Due to the value of entertainment, video games have no pressure or fear of evaluation methods which might prevent learners from engaging in using the language.

Research shows a connection between the video games and experiential learning of a target language. The connection between the video games and the concept "informal learning" was viewed by researchers to have a clear grasp of the concept. For example, Cedefop (2009) 
defines informal learning by the "learning resulting from daily activities related to work, family or leisure. It is not organized or structured in terms of objectives, time or learning support. Informal learning is mostly unintentional from the learner's perspective" (Cedefop, 2009, p. 74).

Similarly, Cross (2007) describes informal learning as something that can happen both intentionally and unintentionally. Moreover, informal learning is not based on regular curriculums and considered to be never ending. Finally, Livingstone (2001) states that informal learning is based on learning situations which are incidental and spontaneous, which does not require a sustained reference such as traditional curriculums.

From the definitions above, it can be concluded that recreational video games can be fitted into this category of learning the features it holds. In other words, video games are spontaneous in nature with no pressure regarding examinations or assessment, as it is not based on a curriculum with specific objectives and is considered to be a non-ending source with key motivation towards video games that helps in engaging learners in the game.

The relationship between video games and learning has been the topic of many studies. Most of the studies consider the usefulness of video games in terms of improving English language skills. For instance, De Silva (2014) stated in his article that video games tend to implant receptive skills by presenting new vocabulary to players. They also provide them with the appropriate context. Moreover, video games simulate the senses of players by showing congruous images and have the game character performs identical actions (De Silva, 2014).

In a similar vein, Rankin (2008) examined the famous MMORPGS (Massively Multiplayer Online Role-Play Games) and found that a better form of language acquisition can be made by giving non-native players a chance to communicate within an international community of players. This allows the players to interact with native speakers, which helps them develop their interpersonal skills and enables them to make functional usage of the target language. Moreover, an article by Reinders and Wattana (2011) "Learn English or die: The effects of digital games on interaction and willingness to communicate in a foreign language", was cited by Chen and Johnson (2004). This study indicates that taking a role-playing game then modifying it to present a language learning aspect to "promote a state of flow and motivate students to practice language skills". They found that learners have a better chance to acquire the secondary skills depending on the amount of experience that the learner has with playing games. From the perspective of this study, Reinders and Wattana (2011) state that to have an effective language acquisition, a learner must produce a "comprehensible output" along with receiving "comprehensible input" of the target language. In addition, Reinders and Wattana (2011) commented on this statement by stating that this requirement fits certain video games perfectly. Since the majority of them provide a wide range of vocabulary and the player are given opportunities to use that vocabulary and communicate with other players.

I n relation to vocabulary acquisition, Piirainen, Marsh and Tainio (2009) argued that repeating lexical and prosodic of video games can help improving an EFL learner's competence either linguistic or interactional. Moreover, repetition in game texts, such as voiced conversations between characters along with written messages can lead to vocabulary 
learning, while interacting with other players during game play improves interactional skills of the players.

One of the few studies which examines the learner's perspective on game enhancing and game-based learning was the study by Chik (2012), which showed that players of video games are able to identify three features of video game activities related to potential foreign language learning. The first feature is acquisition of in-game words and texts, such as a game character's dialogue. The second feature is interacting with other players in-game which provides the opportunities for authentic English language conversations. The third feature being participating in game related discussions, along with reading game related tasks within the game.

Reviewing studies on this topic shows that there is a serious dearth of empirical evidence in the Saudi EFL context. Hence, it is important to understand the impact of the video games on the language learners' motivation for learning English language. This study aims to bridge that gap in the literature by answering the key research questions.

1. Do video games (both online and consul based) have motivational influence on learning English language in the Saudi EFL context?

2. Can teachers consider video games as a tool of motivating new generation of English language learners?

\section{Methodology}

In order to measure the influence of video games on the learners' motivation for learning the English language, the method chosen for this study is a survey questionnaire. The choice of survey questionnaire was influenced by the English-language version of the (AMTB) Attitude/motivation Test Battery(Gardner 2004) and the questions were modified to 10 main questions, along with four questions to investigate personal aspect of the trainees, which included age, hours spent on gaming, most played games, and the game devices -consulused).

The participants of this study were 86 college trainees at Abha college of technology. The average age of the trainees was between $19-22$, which were the majority (72 trainees), and a few participants were between 23-24, about 15 trainees.

\section{Findings}

When asked about playing video games, 75 trainees answered yes, whereas 11 stated that they did not prefer playing video games. When asked about the amount of time spent on playing video games daily, 39 trainees stated that they played one-three hours on average. Whereas 35 trainees stated that they played about four hours and above daily, which clarified the large amount of time spent on playing and the addictive statues of these games especially online games as the trainees responded in the questionnaire. Similarly, 24 trainees admitted 
playing more than four hours daily on a popular online game.

The trainee participants were asked to point out the most played video games. The majority of trainees stated that online interactive games were the number one choice to spend a considerable amount of time. The online multiplayer game Player Unknown's Battlegrounds or what is known as (PUBG), which was developed and published by PUBG Corporation (Wikipedia) came in the top played video game among the trainee participants. Moreover, 54 trainees admitted playing this game in multiple consoles. In this game, players interact with missions, maps, gaming tools, such as military equipment, and other random players around the world. The players listen, read, and present verbal conversations in English in order to win the game.

The second video game in terms of popularity was FIFA, a football simulation video game developed by EA Vancouver as part of Electronic Arts' FIFA series (Wikipedia). Among other respondents, 36 trainees stated that they played this video game on multiple consoles. In this game, players interacted with written English presented in player names and created the team lineup, along with substituting players within the game. Also, they get a chance to listen to an English language commentator on the football match.

A similar online game that was as a favorable as a favorable choice was Fortnite, which is an online video game developed by Epic Games and released in 2017 (Wikipedia). Among other respondents, 15 trainees played this game online with friends and other players around the world with English language as the means of communication.

Lastly, around 26 respondents stated that they played other random video games which some of them have an English language platform such as (Red Dead Redemption) or simple games, such as Candy crush, Clash of Clans.

When asked about the gaming consoles used by the trainees, 59 respondents chose the smart phone to play particular games. Also using another console which was a Play Station-4, 53 trainees stated that they used this console for playing with friends locally and internationally, and only two trainees chosen Xbox as the preferred gaming console.

The findings indicates that the availability of certain games as free downloadable versions (e.g., PUBG, Fortnite) was a major factor of its popularity among the trainees along with its online participatory nature. This availability made these games the favorable choice among the majority of trainees.

\section{Discussion of the Findings}

The participates were asked 10 questions. The means of measuring their attitudes were five choices beginning from (strongly agree, agree, neutral, disagree, strongly disagree). The participants were briefly instructed on how to process the survey and how to conduct the information required. The participants were also given enough time to answer individually, then an open discussion took place after the survey to collect additional data related to attitudes and opinions. The results were as follow: 
Q1: English language is an exciting experience when I watch video games.

$51 \%$ of the participates agreed on the excitement value of the English language presented in the video games. The respondents stated that they found the English material presented in the storyline, names, dialogues, written instructions were formatted in an organized and exciting pattern. $33 \%$ of participates showed neutral opinions on this point and $16 \%$ of them disagreed.

Q2: I can learn new English words/phrases from video games.

Surprisingly, $82 \%$ of respondents agreed on the fact that they learned new words along with phrases either in written form or verbally presented in dialogues between gaming characters. On the other hand, about $14 \%$ of them remained neutral and only $4 \%$ of respondents disagreed on this point.

Q3: I repeat English words/phrases which I hear in video games.

In response to this statement, $64 \%$ of the respondents agreed and stated that they usually repeat words and phrases in English during game play, especially on online interaction between friends or other online players. Other $22 \%$ showed neutral behavior towards repeating words and phrases and $16 \%$ disagreed and stated that there were only there for the recreational purpose.

Q4: I can understand/follow written instructions in English when I watch video games.

Dealing with written material was considered a challenge among learners during authentic teaching situations. For this category, about $47 \%$ of the respondents agreed on understanding what is written as instructions or settings in the game and followed on to complete the gaming tasks presented. $32 \%$ of them preferred to be neutral towards comprehending written material in the game whereas with $21 \%$ of them disagreed and stated that they usually skipped written instructions altogether.

Q5: I can understand/follow audio instructions in English while watching video games.

Surprisingly, only $42 \%$ agreed on their ability to follow audio instructions within a game. When respondents were asked the reason why this occurred, their answers varied from long and boring dialogs or the fast pace instructions were being presented. Moreover, the complicated phrases shown in adventure games with the trend of middle ages English language, which the respondents were not familiar with. For these reasons, $34 \%$ of participants stayed neutral and $24 \%$ disagreed and focused mainly on the gaming process instead.

Q6: I like to hear native speakers of English interact in an online video game.

With the popularity and widespread use of MMORPGS games among players from around the globe, $41 \%$ of the respondents agreed on preferring to hear native speakers interact within this type of games. There were $24 \%$ respondents who preferred to remain neutral and about $37 \%$ disagreed on this point. When asked the reason, the respondents stated that due to the fast pace with which gamers used to speak and the different accents as well as the use of 
slang hindered their understanding of what was being said during the game. Therefore, the majority of the respondents tended to focus on the game itself.

Q7: I want to communicate in English with foreign players in an online video game.

Amazingly, with all the hesitation and fear of communicating with other players, about $69 \%$ respondents agreed that they were internally motivated to speak in English with other players. Moreover, they stated that communicating with native speakers was an enjoyable experience, which gave them a chance to advance their gaming ability along with their communicative skills. Due to this condition, they were equipped with the proper training in English language to overcome the shyness and fear of committing mistakes. However, $22 \%$ of them preferred to stay neutral and only $9 \%$ disagreed and showed no interest in communicating with native speakers.

Q8: I want to learn more English language to play new and online video games.

Here the participates showed significant motivation towards learning English language for the purpose of playing video games. Almost $72 \%$ agreed on being motivated to learn English language to improve their ability in communicating with international players and to be among the first to obtain and review new releases of video games. They showed willingness to learn in either authentic learning situations as in college courses or by self -study in order to achieve this particular goal. $16 \%$ of the respondents remained neutral and only $12 \%$ did not consider it a goal to motivate them to learn.

Q9: Video games helped me improve my English language.

In terms of being a factor in improving English language as an informal way of teaching, 57\% stated that video games actually improved their English language in terms of providing new vocabulary and repeating certain phrases verbally from dialogues to be used both in gaming satiations and in real life with friends. On the other hand, $26 \%$ preferred to remain neutral towards this idea and $17 \%$ disagreed for the reason to focus on the game itself.

Q10: I started to like English language.

In terms of overall motivation towards English language, $43 \%$ of the respondents admitted having a positive change in motivation towards English as a forging language after being engaged with video games. $22 \%$ stated their neutral opinions on this idea. When they were asked the reason for being neutral, they pointed out that already had a good attitude towards English language. Therefore, video games were not a new concept for them in terms of motivation. Meanwhile, $35 \%$ of them disagreed and stated that no improvement in motivation towards video games was made and the recreation was the sole purpose of playing the video games.

\section{Conclusions}

This study has looked into the use of video games among adult learners of English language in the Saudi EFL context. The study adopted a questionnaire that helped generate the 
quantitative responses of the participants. The chief aim of the questionnaire was to investigate the influence of the video games on the EFL learners' motivation in the Saudi context. The key findings include:

1- Modern MMORPGS games are available on multi-consoles including Smart phones with free downloadable features, which explain the variety of these specific games and the growing culture to certain names in the video game industry.

2- The study shows a huge demand for online video games with a considerable amount of time spent on playing them each day with direct interaction between players.

4- There is a strong evidence of the positive impact of video games on the motivation of English language learners in general.

5- Most positive aspects were due to the interactive environment, such as visual instructions, verbal communication, and conversations between players.

6- The trainees showed interest in learning English language to enhance their communicative ability and engage more in online video games.

7- The trainees admitted being familiarized with the English language environment presented in the video games, such as historical events, certain countries and cities, and famous characters.

8- They study found out that trainees learned, and repeated new vocabulary provided by the video games. Moreover, pronouncing lines and sentences which were being heard in the video games, trainees were willing to communicate and interact in online video games, but with hesitation to interact with some native speakers due to the speed and use of slang language, which hidered their understanding. As a result, they would lose focus and the game itself. In addition, the trainees were motivated to learn English language in order to experience new releases of video games and to be among the first ones to discover the features of the new game and to be a source of evaluating and instructing other gamers to the new video game.

\section{References}

Cedefop. (2009). European guidelines for validating non-formal and informal learning. Luxembourg: Publications Office.

Chen, M., \& Johnson, S. (2004). Measuring flow in a computer game simulating a foreign language environment. Retrieved March 8, 2019, from http://www.markdangerchen.net/pubs/flow_in_game_simulating_fle.pdf

Chik, A. (2012). Digital gameplay for autonomous foreign language learning: Gamers' and language teachers' perspectives. In H. Reinders (Ed.), Digital games in language learning and teaching (pp. 95-114). London: Palgrave Macmillan UK.

https://doi.org/10.1057/9781137005267_6 
CLARK, C. (2000). Innovative Strategy: Concept cartoons. Instructional and Learning Strategies. Available from http://www.southalabama.edu/coe/bset/dempsey/isd613/stuproj/summer00is/caryclark.pdf (accessed on August 10, 2019).

Da Silva, R. L. (2014). Video Games as Opportunity for Informal English Language Learning: Theoretical Considerations. The ESPecialist, 35(2), 155-169, 1-15. Available from: http://revistaspucsp.br/index.php/esp/article/viewFile/21465/15692

Doring, A. (2002). The use of cartoons as a teaching and learning strategy with adult learners. Journal of Adult Learning, 30(1), 56-62.

Gardner, R. C. (1985). Social psychology and second language learning: The role of attitudes and motivation. London: Edward Arnold Publishers.

Gardner, R. C. (2004). Attitude/Motivation Test Battery: International AMTB Research Project. Ontario: The University of Western Ontario, Canada.

Harmer, J. (1991). The practice of English language teaching. London: Longman.

Parsons, R., Hinson, S., \& Brown, D. (2001). Educational psychology: practitioner researcher models of teaching. University of Virginia: Wadsworth Thomson Learning.

Piirainen-Marsh, A., \& Tainio, L. (2009). Other-repetition as a resource for participation in the activity of playing a video game. The Modern Language Journal, 93(2), 153-169. https://doi.org/10.1111/j.1540 4781.2009.00853.x

Rankin, Y. A. et al. (2006). 3D Role-Playing Games as Language Learning Tools. Eurographics, v. 25-3.

Reinders, H., \& Wattana, S. (2011). Learn English or Die: The effects of digital games on interaction and willingness to communicate in a foreign language. Digital Culture \& Education, 3:1, 3-29. From http://www.digitalcultureandeducation.com/cms/wp content/uploads/2011/04/dce1049_reinders_2011.pdf

Ryan, R. M., \& Deci, E. L. (2000). Intrinsic and extrinsic motivations: Classic definitions and new directions doi://doi.org/10.1006/ceps.1999.1020.

Ryan, R. M., Rigby, C. S., \& Przybylski, A. (2006). The motivational pull of video games: A self determination theory approach. Motivation and Emotion, 30(4), 344-360. https://doi.org/10.1007/s11031006-9051-8

S, D. R. (2017). INFLUENCE OF VIDEO GAMES ON THE ACAUISITION OF THE ENGLISH LANGUGAE. Vilnius University: institute of Foregin Languges .

Väisänen, A.-P. (2018). LEARNING ENGLISH THROUGH VIDEO GAMES: Finnish Learners' Experiences. University of Jyväskylä: Department of Language and Communication Studies.

Whitton, N. (2010). Learning with digital games : A practical guide to engaging students in 
higher education. New York: Routledge. Retrieved from https://jyu.finna.fi/Record/jykdok.1124319

Wikipedia. (2019, October 21). FIFA19. Retrieved September 6, 2019, from Wikipedia, the free encyclopedia: https://en.wikipedia.org/wiki/FIFA_19

Wikipedia. (2019, October 22). Fortnite Battle Royale. Retrieved September 6, 2019, from Wikipedia, the free encyclopedia: https://en.wikipedia.org/wiki/Fortnite_Battle_Royale

Wikipedia, t. f. (2019, October 10). PlayerUnknown's Battlegrounds. Retrieved September 8, 2019, from Wikipedia: https://en.wikipedia.org/wiki/PlayerUnknown's_Battlegrounds

\section{Copyright Disclaimer}

Copyright for this article is retained by the author(s), with first publication rights granted to the journal.

This is an open-access article distributed under the terms and conditions of the Creative Commons Attribution license (http://creativecommons.org/licenses/by/3.0/). 